\title{
Accessibility in Mobile Applications of Portuguese Public Administration
}

\author{
Marcos Carneiro ${ }^{1}$, Frederico Branco ${ }^{2}$, Ramiro Gonçalves ${ }^{2}$, \\ Manuel Au-Yong-Oliveira ${ }^{4}$, Fernando Moreira ${ }^{5}$, \\ and José Martins ${ }^{2,3(\square)}$ \\ 1 University of Trás-os-Montes e Alto Douro, Vila Real, Portugal \\ a151388@utad.eu \\ 2 INESC TEC and UTAD, Vila Real, Portugal \\ \{fbranco, ramiro, jmartins\}@utad.pt \\ ${ }^{3}$ Polytechnique Institute of Bragança - EsACT, Mirandela, Portugal \\ ${ }^{4}$ GOVCOPP, Department of Economics, Management, Industrial Engineering \\ and Tourism, University of Aveiro, 3810-193 Aveiro, Portugal \\ mao@ua.pt \\ ${ }^{5}$ Research on Economics, Management and Information Technologies - \\ REMIT, Univ Portucalense, Portucalense Institute for Legal Research - IJP, \\ Porto, Portugal \\ fmoreira@upt.pt
}

\begin{abstract}
Today's society presents a fast development marked by the digital era, where the sharing, disclosure and access to information is made through information and communication technologies.

The use of mobile applications is growing exponentially, spreading to the most varied social classes and everyday activity areas. Worldwide, its use in the most variety of services, has been increasing significantly. Given that, it is essential that mobile applications are accessible in a way that allows access conditions and equal opportunities to all the users.

With this study we present indicators regarding the state of accessibility in mobile applications through the evaluation of five Portuguese public administration applications. The methodology used was a fully manual evaluation through a proposal of a model of evaluation divided by quantitative and qualitative requirements created by us, as well as the use of functionalities such as VoiceOver and TalkBack.

Taking into account that the study initially proposed on accessibility in mobile applications is the first to be carried out in Portugal and one of the few currently worldwide, it is believed that its content may help, in some way, to raise awareness of the state of accessibility in the Portuguese mobile applications, to create measures that make these applications more accessible to all and that this work could be taken into account in future studies of the topic.
\end{abstract}

Keywords: Accessibility - Mobile apps - Accessibility mobile apps ·

WCAG $2.0 \cdot \mathrm{W} 3 \mathrm{C} \cdot$ Public administration

(C) Springer Nature Switzerland AG 2019

P. Zaphiris and A. Ioannou (Eds.): HCII 2019, LNCS 11591, pp. 243-256, 2019.

https://doi.org/10.1007/978-3-030-21817-1_19

fbranco@utad.pt 


\section{Introduction}

The existing literature about accessibility in the mobile apps don't show enough studies that aim the comprehension and evaluation of accessibility of the mobile apps. The fact that there aren't enough studies and knowledge about this topic, were the main factors that motivated the present article. Also, there were some other facts like the growth of the global use of these mobile devices and consequently the use of mobile apps for all kind of day-a-day activities.

According to (WHO 2018), there are more than a million people that have some sort of disabilities, what translates to $15 \%$ of the world population. In Europe, according to the data that was collected by the European Union, there are more than 80 million people in the same situation (EU-FRA 2017). In Portugal, there are more than a million people that which have some sort of disabilities, more specifically 980 thousand that can't walk or climb stairs, 27 thousand that can't see and 26 thousand that can't hear (GEP 2016).

In the current society of information its common the preoccupation of universal access to the various services through the digital environments, having as objective to improve the quality of life of the users. Although, this access may end up be conditioned because specific groups of our society may face problems of accessibility, eventually being excluded from the advantages that this new society brings. The first time that Web Accessibility was taken into consideration at European level it was in September 25 of 2001, where the theme of action plan was the "eEurope 2002" (Comissão Europeia 2014). Although, at World level, the Web Accessibility was already being referenced when W3C created in 1997 the Web Accessibility Initiative program (W3C 2009).

Relatively to the accessibility on mobile apps, this is a new topic and something where there aren't many studies to take conclusions. Also, there aren't many guidelines or requirements to be followed in order to make them accessible to everyone.

Considering the things previously said, what we pretend with this paper is to present and discuss the results of the evaluations made to the apps with an adapted approach of the WCAG 2.0 Guidelines of Web Accessibility to the mobile apps context and some good practices, contributing to the increase of knowledge of this topic.

\section{Mobile Accessibility - Current State of Things}

\subsection{Conceptualizing Accessibility}

Accessibility can be defined by the possibility of people that have some sort of disabilities, incapacities or limitations use one specific resource or product in the same way as a person without these particularities (Henry 2007).

The World Wide Web provide an abundance of services and information's to a large group of users. Her fast growth contributed to the formation for actual formation of the society highly focused on information. In the specific context of Web, Accessibility can be related to the application of concepts of the general accessibility in the 
digital environment, making the web and the devices useful to every user, providing maximum flexibility in order to adapt to the user's needs (Clark 2003).

To (Henry 2007), "an accessible Web means that the people with some sort of disabilities can use the Web". It is intended that people can understand, navigate and interact with the web and even contribute to the Web. Beyond this, the Web accessibility can benefit the others with some limitations like older people that with the advance of the tears they lose some of their capabilities due to aging (Thatcher et al. 2006).

\subsection{Mobile Apps Accessibility}

Being that the smartphones market is growing fast, there is the necessity of exploring and develop this kind of devices to meet the demand (Lecheta 2010). With that being said, we can define a smartphone as a mobile that it has evolved capabilities and characteristics of a personal computer (Santhipriya et al. 2011).

According to W3C (W3C 2017a), the mobile accessibility aims to make the websites and the apps more accessible to people with some sort of disabilities either these are using their mobile phone or other devices like tablets, digital televisions, smartwatches, among others.

To develop an application, its necessary to think how the users with disabilities or special necessities will use that application with assistive technologies. Some of other concerns are questions like the contrast and the size of the clickable zones that are very important, and their implementation and respect should be followed on the development of the apps so, it is necessary to define requirements that are fundamental to create accessible content.

\subsection{Legal Rules and Regulations}

World Wide Accessibility Norms and Regulation

As we previously said, to make the world more accessible to everyone it's necessary to define requirements and guidelines that must be followed. So, to achieve this, were implemented norms and regulations by various internationals organizations and countries like United Nations, EUA, European Union and Portugal.

United Nations approved on 13 of December of 2006 a convention that gives instructions to 160 countries to take measures that guarantees the access to people with disabilities on an equal basis with the others, to the information and services provided to public (Nações Unidas 2006).

EUA have some laws for accessibility like Rehabilitation law of 1973, Americans with Disabilities Act (ADA) (ADA n.d.) and the Individual with Disabilities Education Act (IDEA) (IDEA n.d.).

In European Union there are national legislations that coexists with several European legislation for accessibility like, for example, countries like France, England or Ireland have their own laws for this subject. So, the European council in 2010 propose actions like a systematic evaluation to Web services so the laws could be updated more frequently, and public services would be more accessible in 2015 for every country in Europe (Comissão Europeia 2010). In December of 2010, the ratification of the convention of the rights of people with disabilities and the adoption of WCAG 2.0 were 
announced (Comissão Europeia 2014). In 13 of December of 2012 the European Commission, through the proposal for a directive about accessibility on the websites of organism of the public sector, wrote in the digital agenda a set of mandatory directives, to websites of public organisms (Comissão Europeia 2012). These new rules represent a try to improve the accessibility web in the organism of the state. At 2 of December of 2016 the European Parliament and the European council published a directive called 2016/2102 related to the accessibility on the websites and the mobile apps of the organism of public sector (Parlamento Europeu and Conselho Europeu 2016).

In Portugal it was created in 1999, through the RCM 96/99 the national initiative to the citizens with special needs in the information society (DRE 1999). In June of 2000, the European council endorsed the "e-Europe 2002" action plan, covering the Portuguese initiative for the 15 European countries (Comissão Europeia 2000). In 2007 through the RCM 155/2007, it was defined that the level of conformity A of WCAG 1.0 was required for most web sites, and the AA level for thores that entail the provision of transactional services (DRE 2007). In 2012 through RCM 91/2012 and it was determined that all websites that provide only information are obligated to comply with level A of WCAG 2.0 and that all websites that provide online services are obligated to comply with AA level of WCAG 2.0 (DRE 2012). More recently, it was published a new law n $n^{\circ} 83 / 2018$ relatively to a definition of requirements of accessibility to Websites and mobile applications of the public sector, although this law only applies in 2019 (DRE 2018).

\section{WCAG Norms}

The World Wide Web Consortium (W3C) is an non-profit organization funded in 1994 by Tim Berners-Lee having as objective "develop standards and directives that ensure the growth in a long term of the Web". (W3C 2017b). So, in 1997, this organization propose the WAI (Web Accessibility Initiative) where their main objective was to allow the access to the various websites, independently of their users needs (W3C 2009). In 1999 it was launched the first version of WCAG which contained 14 directives and several checkpoints that could be used to determine the accessibility of a web page (W3C 1999). Over the years, were emerging new Web technologies, whereby the WCAG 1.0 started to present difficulties. In order to overcome these difficulties, in 2008 was published the second version of WCAG, in which came establish the international standard introducing a change to the rules in order to make them neutral and always updated, so they created 4 basic principles (W3C 2008). The first principle is perceptible, the second one is operable, the third one is understandable, the last one is robust. In order to say that something is considered accessible, these principals must be verified, necessarily. Recently the W3C published the WCAG 2.1 which has 17 new success criteria (W3C 2018). These changes are mainly in the accessibility of Web content so there have not yet been major changes in the Accessibility of mobile applications. However, the $\mathrm{W} 3 \mathrm{C}$ provides a section recently created for the mobile accessibility (W3C 2015). This section is still quite limited because it is an adaptation of the Web Accessibility model, and only provides informative guidelines and not necessarily requirements. As in Web Accessibility, there are 4 basic principles: perceivability, operability, comprehension, and robustness of content. 
We can verify that there is work being done in this type of accessibility. However, this work ends up being reduced because great part of these criteria and guidelines are adapted from the Web Accessibility. Furthermore, Google and iOS published a set of good practices to the developers, in order to make the apps more accessible.

Android and iOS Good Practices

In addition to the previously W3C guidelines, the Google and the Apple provide a list of good practices of Accessibility on the development of the applications. In the case of Google, they present a list with some good practices that should be followed by the developers to make the applications accessible. The first one is that all applications must show some descriptive text of the user interface controls. The second one is that audio solicitation must be followed by visual solicitations. The third one says that the clickable area of elements must be bigger than $9 \times 9 \mathrm{~mm}$. The forth is about the contrast between background and foreground, and it should be at least 4:5:1. And the last one is for test the accessibility using the "TalkBack" (Google n.d.-a).

In the case of the Apple and the operating system they present some good practices that should be followed. The first one says to give some descriptive text to the elements of interface in order to support screen read. The second one says that is a need to notify every time that is a change in the elements of interface. And the last one is for test the accessibility using "VoiceOver" (Apple 2012).

\subsection{Portuguese Perspective on Accessibility}

The first studies founded about this topic are evaluations carried out by Accenture (1st Edition) and 2003 (2nd Edition) to the sites of Public Administration entities (Accenture 2003). Another study was "Relatório Vector21 sobre Acessibilidade Web em Portugal", translated "Report Vector21 about Web Accessibility in Portugal", having as objective testing web accessibility in Portugal through the analyses to a group of 200 websites of Public Administration (Vector 21 2008).

There are also several research projects that have been devoted to this subject, like for example "Avaliação da Acessibilidade dos Sítios Web das Empresas Portuguesa" (Martins 2008), "Acessibilidade dos Conteúdos Web dos Municípios Portugueses" (Fernandes 2009), "Acessibilidade Web: Ponto de situação das Maiores Empresas Portuguesas" (Gonçalves et al. 2009), "Estudo sobre o estado da Acessibilidade dos sítios Web dos estabelecimentos de Ensino superior" (Fernandes and Cardoso 2013), "A Acessibilidade das Plataformas de e-learning em Instituições de Ensino Superior Público em Portugal: Contributos Iniciais" (Tomás 2014), "Acessibilidade dos Conteúdos Web no Setor da Saúde" (Moreira 2014), "A review on the Portuguese Enterprises Web Accessibility Levels - A website accessibility high level improvement proposal" (Goncalves et al. 2014) and "AccessWeb- Uma perspective sobre a Acessibilidade Web em Portugal” (Ramiro et al. 2015). 


\section{Accessibility Evaluation of Mobile Applications}

The guidelines for this section aren't enough and are very ambiguous so it was necessary to create a model of evaluation, presented in (Table 1), with an adaptation of the WCAG 2.0 mobile recommendations section, as well as some good practices of both operating systems and a checklist from a study (Apple n.d.-b; Google n.d.-b; W3C 2015; White 2015).

Table 1. Adaptation of WCAG 2.0 mobile guidelines, iOS and Google good practices and thesis model (Apple n.d.-b; Google n.d.-b; W3C 2015; White 2015).

\begin{tabular}{l|l|l}
\hline Requirements & Context & Reference \\
\hline Quantitative requirement/Guidelines & \multicolumn{2}{l}{} \\
\hline REQ01 & Size of the buttons of action $<9 \times 9 \mathrm{~mm}$ & $\begin{array}{l}\text { W3C Mobile and } \\
\text { Google/iOS }\end{array}$ \\
\hline REQ02 & Size of selected text $<9 \times 9 \mathrm{~mm}$ & $\begin{array}{l}\text { W3C Mobile and } \\
\text { Google/iOS }\end{array}$ \\
\hline REQ03 & Spacing $<2 \mathrm{~mm}$ & $\begin{array}{l}\text { W3C Mobile and } \\
\text { Google/iOS }\end{array}$ \\
\hline REQ04 & Contrast Errors AA (ratio 4.5:1) & W3C Mobile \\
\hline REQ05 & Contrast Errors AAA (ratio 7:1) & W3C Mobile \\
\hline Qualitative requirements/Guidelines & W3C Mobile \\
\hline REQ06 & Increase the size of the text & W3C Mobile \\
\hline REQ07 & Do zoom & Thesis Model \\
\hline REQ08 & Color to grayscale & Thesis Model \\
\hline REQ10 & Invert the colors & Thesis Model \\
\hline REQ11 & $\begin{array}{l}\text { Remove the color of emphasized } \\
\text { information }\end{array}$ & Google \\
\hline REQ11A & Compatibility with the TalkBack & Thesis Model and iOS \\
\hline REQ12 & Supports both orientations & W3C Mobile \\
\hline REQ13 & $\begin{array}{l}\text { Non-textual content also available in a text } \\
\text { form }\end{array}$ & $\begin{array}{l}\text { Thesis Model } \\
\text { iOS/Google }\end{array}$ \\
\hline REQ14 & $\begin{array}{l}\text { Clear indication that the elements are } \\
\text { actionable }\end{array}$ & W3C Mobile \\
\hline REQ15 & Use of simple and direct language & and \\
\hline
\end{tabular}

\subsection{Evaluation Procedure}

There are in the market a wide variety of Android devices either in terms of sizes, of display, thickness, among others. Unlike Android smartphones, iPhones exist in limited models and are controlled by the same provider which in some way limits the differences in terms of characteristics between these devices. The tests on the two devices were made according to the following circumstances: same level of intensity and 
environment brightness and operating system not too outdated. In terms of requirements for the selection of the devices, there weren't any because the main objective with this study was to obtain results and an idea of the state of this kind of accessibility and not making a comparison between both operating systems. In the table Table 2 are the characteristics of both devices used in this study:

Table 2. Mobile devices characteristics

\begin{tabular}{l|l|l|l|l|l}
\hline Device & OS & Display & CPU & Weight & Year \\
\hline Vodafone Smart Prime 7 & Android 6.0.1 & $720 \times 1280 \mathrm{p}$ and 5' & $1.8 \mathrm{Ghz}$ & $120 \mathrm{~g}$ & 2016 \\
\hline iPhone 4S & iOS 9.3.5 & $960 \times 640 \mathrm{p}$ and 3,5' & $1 \mathrm{Ghz}$ & $140 \mathrm{~g}$ & 2011 \\
\hline
\end{tabular}

Relatively to the evaluation method used in the present work, it was done through a manual evaluation with the help of two functionalities each one present in the respective device and one application to make the contrast evaluation.

We used the model previously mentioned, as well as a Likert scale from 1 to 7 for the quantitative evaluation where the classification 1 corresponds to the minimum of the evaluation and the 7 to the maximum (Harry et al. 2012). In addition, it was necessary to use a qualitative evaluation to some requirements that couldn't be quantified (Wainer 2018). We used a verification of these requirements in both systems and posteriorly presented some consequences of the disrespect of these requirements. device.

\subsection{Tools/Functionalities for Evaluating Accessibility of Mobile Apps}

The tools of automatic evaluation of accessibility were created to assist the developers of websites and mobile applications to apply simplicity the directives of accessibility (Ivory et al. 2003). Although there are many tools to do an automatic evaluation of web accessibility, there aren't any capable of doing a complete evaluation of the mobile applications accessibility. However there is a tool called Accessibility Scanner developed by Google that only evaluates some requirements of the different parts of an application through screenshots (Google n.d.-d).

Since there aren't any tools capable of doing an automatic and complete evaluation of the accessibility in the mobile applications, we used the functionalities presented on both systems (TalkBack and VoiceOver). The TalkBack was developed by Google and is a screen reader that allows the user to handle the device without being able to see the display (Google n.d.-c). The VoiceOver was developed by Apple and communicates with the user giving information about what his touching or pressing (Apple n.d.-a).

For the contrast evaluation we used the color contrast application developed by UserLight and uses the WCAG 2.0 directives with regard to contrast of level AA and level AAA (UserLight n.d.). 


\subsection{Target Group}

To these evaluations, there were considered 5 applications of the Portuguese public administration. The first one was the MySNS from National Health Service and has as main objective to allow the users to consult health information and news (SNS n.d.). The second one was IRS 2017 from Tax Authority and has as main objective to allow the users to do and give the tax documents through the mobile device (Autoridade Tributária n.d.). The third one was MyAdse from ADSE and has as main objective to simplify all the available services through a digital card (ADSE n.d.). The fourth was the iMetro of Porto from metro of Porto and has as main objective to provide real time schedules, frequencies and state of the lines (Metro do Porto n.d.). The last one was the município of Vila Real developed by the municipality and has as main objective to provide information regarding future events, contacts and points of interest of the city (CMVilaReal n.d.).

\section{Mobile Apps Accessibility Evaluation Results}

As mentioned before, these evaluations were divided by quantitative and qualitative requirements. Firstly, we evaluated all the quantitative requirements in the iOS operating system through the VoiceOver functionality. All the classifications can be observed on the Table 3 .

Table 3. Classification of the quantitative requirements on the iOS system

\begin{tabular}{l|l|l|l|l|l}
\hline Requirements & MySNS & $\begin{array}{l}\text { Municipio of Vila } \\
\text { Real }\end{array}$ & MyADSE & $\begin{array}{l}\text { iMetro of } \\
\text { Porto }\end{array}$ & $\begin{array}{l}\text { IRS } \\
2017\end{array}$ \\
\hline $\begin{array}{l}\text { Size of clickable } \\
\text { areas }<9 \mathrm{~mm}\end{array}$ & 1 & 5 & 1 & 5 & 6 \\
\hline $\begin{array}{l}\text { Size of action } \\
\text { buttons }<9 \mathrm{~mm}\end{array}$ & 2 & 6 & 4 & 6 & 6 \\
\hline Spacing & 1 & 2 & 1 & 1 & 3 \\
\hline Contrast AA & 1 & 1 & 2 & 2 & 3 \\
\hline Contrast AAA & 1 & 1 & 1 & 1 & 1 \\
\hline Total & 1 & 3 & 2 & 3 & 4 \\
\hline
\end{tabular}

We can verify that in the evaluation of the quantitative requirements on the iOS system, the app IRS 2017 obtained the best classification and the app MySNS obtained the worst classification.

Relatively to the evaluation of the quantitative requirements on the Android system, we can observe the results on the Table 4 . 
Table 4. Classification of the quantitative requirements on the Android system

\begin{tabular}{l|l|l|l|l|l}
\hline Requirements & MySNS & $\begin{array}{l}\text { Municipio of Vila } \\
\text { Real }\end{array}$ & MyADSE & $\begin{array}{l}\text { iMetro of } \\
\text { Porto }\end{array}$ & $\begin{array}{l}\text { IRS } \\
2017\end{array}$ \\
\hline $\begin{array}{l}\text { Size of clickable } \\
\text { areas }<9 \mathrm{~mm}\end{array}$ & 1 & 3 & 1 & 6 & 4 \\
\hline $\begin{array}{l}\text { Size of action } \\
\text { buttons }<9 \mathrm{~mm}\end{array}$ & 3 & 6 & 6 & 6 & 7 \\
\hline Spacing & 1 & 4 & 1 & 5 & 5 \\
\hline Contrast AA & 1 & 1 & 2 & 5 & 3 \\
\hline Contrast AAA & 1 & 1 & 1 & 1 & 1 \\
\hline Total & 1 & 3 & 2 & 5 & 4 \\
\hline
\end{tabular}

We can verify that in the Android system the application iMetro of Porto obtained the best classification and the application MySNS obtained the worst classification.

After all the quantitative questions were evaluated, we proceed to the qualitative ones. In the Table 5, are the results of the evaluation on iOS system

Table 5. Classification of the qualitative requirements on the iOS system

\begin{tabular}{l|l|l}
\hline \multirow{2}{*}{ Requirements } & \multicolumn{2}{l}{ Verification } \\
\cline { 2 - 3 } & Yes & No \\
\hline REQ06 & 1 & 4 \\
\hline REQ07 & 0 & 5 \\
\hline REQ08 & 0 & 5 \\
\hline REQ09 & 0 & 5 \\
\hline REQ10 & 0 & 5 \\
\hline REQ11A & 1 & 4 \\
\hline REQ12 & 0 & 5 \\
\hline REQ13 & 2 & 3 \\
\hline REQ14 & 5 & 0 \\
\hline REQ15 & 3 & 2 \\
\hline
\end{tabular}

Analyzing the results on the iOS system, we can verify that there aren't any extra functionalities that allows the user to increase the size of the text, making zoom, convert to grayscale, invert the colors or take the colors of emphasized text with the exception of Municipio of Vila Real that allows the user to increase the size of the text. Relatively to the compatibility with the VoiceOver functionality, we can verify that only one app is totally compatible with this functionality. Regarding the support of both orientations, we can verify that none of the apps support both orientations. We can also notice that all the applications provide information on the most relevant elements like buttons and links. Lastly, we can verify that the apps that presented more errors on the quantitative requirements are the ones that have more pages and information on their applications.

Then we have on Table 6 the results of the qualitative evaluation on the Android system. 
Table 6. Classification of the qualitative requirements on the android system

\begin{tabular}{l|l|l}
\hline \multirow{2}{*}{ Requirements } & \multicolumn{2}{|l}{ Verification } \\
\cline { 2 - 3 } & Yes & No \\
\hline REQ06 & 1 & 4 \\
\hline REQ07 & 0 & 5 \\
\hline REQ08 & 0 & 5 \\
\hline REQ09 & 0 & 5 \\
\hline REQ10 & 0 & 5 \\
\hline REQ11 & 1 & 4 \\
\hline REQ12 & 0 & 5 \\
\hline REQ13 & 1 & 4 \\
\hline REQ14 & 5 & 0 \\
\hline REQ15 & 3 & 2 \\
\hline
\end{tabular}

In a first look we can verify that the results are very similar to the iOS ones. This is justified by the fact that the interfaces of the applications on both systems are the same, with the exception of the iMetro of Porto.

For the functionalities issues, we can verify that all the apps don't provide any of them with exception of the Municipio of Vila Real that gives us a functionality that allow us to increase the size of the text. Relatively to the compatibility with the TalkBack functionality, we can verify that only one application is completely compatible with this functionality. In the requirement of the support of the app on both orientations (landscape and portrait) we can verify that none of them supports both orientations. The only orientation of this applications is the portrait one what may difficult the handling of these apps. Relatively to the text availability for non-text content, only one application fully covers them. The other apps have issues on the buttons and menus. Regarding if the app provides clear information that the elements are clickable, we can notice that all the apps provide this information on the most relevant elements like buttons and links. Lastly, and like we previously said, we can verify that the apps that presented more errors on the quantitative requirements are the ones that have more pages and information on their applications.

\section{Results Discussion}

In a deep analysis, we can say that the results that we collected from all applications are a reflection of the state of the public administration mobile apps in Portugal. In general, we can affirm that the results obtained are unsatisfactory, observing low classifications and disrespect of most of qualitative requirements. With this, we can say that there is still a lot of work to do in order to make the applications accessible to all. In a particular way, we can say that, in the quantitative questions, the requirements with the worsts classifications were the contrast ones followed by the spacing errors. The ones that presented the best results were the clickable areas and buttons size errors. Relatively to the qualitative questions, we can verify that there isn't in any application (with 
exception of Municipio of Vila Real) that has implemented the several functionalities like zoom, increase the size of the text, greyscale. Also, all the apps in both systems, don't support both orientations.

Between both Android and iOS systems, we can conclude that in a global way the results are very similar. This can be justified by the simple reason that all the interfaces and information of the applications are the same in both systems as well as the detection of the areas of these and the menus, with the exception of iMetro of Porto.

Also, it should be noted that the applications that obtained the worsts classifications in the different requirements are the ones that have a huge number of pages and information.

\section{Conclusions}

Although we had some limitations, the main objective was achieved, and got a view of the actual state of the accessibility in the applications of Portuguese Public Administration. Relatively to the limitations, these were related to the fact that there aren't legal requirements to be followed, as well as there aren't any tools or applications that can do a fully automatic evaluation of accessibility of mobile applications on both systems. It was necessary to make a fully manual evaluation through an adapted model evaluation model. Also, it was necessary to define a new evaluation system since we couldn't evaluate the quantitative requirements with the WCAG methods. It was also necessary to make manual evaluations of all apps with the help of the functionalities presented in both systems (Voice Over and Talkback). For the qualitative requirements we did a verification, on both systems, to know that they had or not a certain requirement.

Since there are many organizations and causes to help and improve life of people with disabilities and with the technological improvement, it was expected better results in terms of accessibility on these applications.

With this being said and looking to the results that we obtained, we can conclude that there is much work to be done in order to make the mobile applications accessible to all. The good practices announced by the Android and Apple as well as the recommendations presented by $\mathrm{W} 3 \mathrm{C}$ to the accessibility on mobile apps are still very limited and there's still a lot of room to improve.

\subsection{Theoretical Implications}

In Portugal the accessibility in mobile applications is, until now, a topic where aren't many studies so, the results and conclusions about the actual state of accessibility is something new. Even if we search about this topic all over the world, there aren't enough studies to take the proper conclusions and compare results. So, with this being said, we couldn't compare these results with any study as well as use some eventual methodology to evaluate these apps. 


\subsection{Practical Implications}

So, with the collected results, we can conclude that the mobile applications of the Portuguese public administration have an unsatisfactory level of accessibility. This has consequences, like for instance people with some sort of difficulties can have problems when trying to handle these applications or can't even handle it at all. That is, these people are being somewhat excluded from these technological worlds.

\subsection{Final Considerations}

The principal objective of this work was, although with some limitations, achieved, where five applications of the Portuguese Public Administration were evaluated. Two of the main reasons for these limitations were the fact that there aren't any legal requirements to be followed in this particularity, as well as the fact that there aren't any applications or tools that make a fully automatic evaluation of the accessibility in the mobile apps. In terms of recommendations, and addition to those presented on the proposal model of evaluation, it is necessary to do a larger study about this topic, is also needed to extend the actual monitorization of accessibility to the mobile applications and also an adoption of some legislations that promotes this accessibility on the applications.

\section{References}

Accenture: Relatório final: Avaliação externa de web sites dos organismos da administração directa e indirecta do estado (segunda ed.). Unidade de Missão Inovação e Conhecimento da Presidência do Conselho de Ministros, Lisboa (2003)

ADA: The Americans with Disabilities Act of 1990 and Revised ADA Regulations Implementing Title II and Title III (n.d.)

ADSE: Já conhece a app MyADSE? (n.d.). https://www2.adse.pt/myadse/

Apple: Accessibility Programming Guide for iOS (2012). https://developer.apple.com/library/ archive/documentation/UserExperience/Conceptual/iPhoneAccessibility/Making_ Application_Accessible/Making_Application_Accessible.html\#//apple_ref/doc/uid/ TP40008785-CH102-SW5

Apple: Accessibility: VoiceOver (n.d.-a). https://www.apple.com/accessibility/iphone/vision/

Apple: Testing for Accessibility on OS X: Using the Accessibility Inspector (n.d.-b). https:// developer.apple.com/library/archive/documentation/Accessibility/Conceptual/ AccessibilityMacOSX/OSXAXTestingApps.html

Autoridade Tributária: IRS 2017 (n.d.). https://play.google.com/store/apps/details?id=pt.gov. portaldasfinancas.irs\&hl=pt_PT

Clark, J.: Understanding Web accessibility (2003). https://joeclark.org/access/webaccess/ JVoluntAdmin.html

CMVilaReal: Município de Vila Real (n.d.). https://play.google.com/store/apps/details?id=com. goodbarber.agendacmvr

Comissão Europeia: eEurope 2002: Projecto de Plano de Acção (2000). https://eur-lex.europa.eu/ legal-content/pt/TXT/PDF/?uri=CELEX:52000DC0330\&rid=13 
Comissão Europeia: COMUNICAÇÃO DA COMISSÃO AO PARLAMENTO EUROPEU, AO CONSELHO, AO COMITÉ ECONÓMICO E SOCIAL EUROPEU E AO COMITÉ DAS REGIÕES: Uma Agenda Digital para a Europa (2010). https://eur-lex.europa.eu/ LexUriServ/LexUriServ.do?uri=COM:2010:0245:FIN:PT:HTML

Comissão Europeia: Comunicado de Imprensa IP/12/1305 (2012). www.europa.eu/rapid/pressrelease_IP-12-1305_pt.pdf

Comissão Europeia: EU Policy (2014). https://ec.europa.eu/ipg/standards/accessibility/eu_ policy/index_en.htm

DRE: PRESIDÊNCIA DO CONSELHO DE MINISTROS: Resolução do Conselho de Ministros n. ${ }^{\circ}$ 96/99 (1999). https://arquivo.pt/wayback/20170823011153/https://www.umic.pt/images/ stories/publicacoes/RCM\%2096\%2099.pdf

DRE: Resolução do Conselho de Ministros n. ${ }^{0}$ 155/2007 (2007). https://dre.pt/pesquisaavancada///asearch/642547/details/maximized?perPage=100\&anoDR=2007\&types= SERIEI\&search=Pesquisar

DRE: Resolução do Conselho de Ministros n. ${ }^{\circ}$ 91/2012 (2012). https://dre.pt/web/guest/pesquisa/ -/search/191863/details/normal?]=1

DRE: Decreto-Lei n. ${ }^{\circ}$ 83/2018 (2018). https://dre.pt/web/guest/pesquisa/-/search/116734769/ details/normal?l=1\&fbclid=IwAR0h2e9QPRkVVm-cDoFWuCv46sJfq611pGQ79xuB0nOtO 3HF8PhxRZanM_M

EU-FRA: People with disabilities (2017). https://fra.europa.eu/en/theme/people-disabilities

Fernandes, J.: Acessibilidade dos conteúdos web dos municípios portugueses (2009)

Fernandes, J., Cardoso, C.: Estudo sobre o estado da acessibilidade dos sítios web dos estabelecimentos de ensino superior (2013)

GEP: Estatísticas sobre Deficiências ou Incapacidades (2016). https://oddh.iscsp.ulisboa.pt/index. php/pt/2013-04-24-18-50-23/outras-publicacoes/item/281-estat\%C3\%ADsticas-sobre-defici $\%$ C3\%AAncias-ou-incapacidades

Goncalves, R., Martins, J., Branco, F.: A review on the Portuguese enterprises web accessibility levels - a website accessibility high level improvement proposal. In: 5th International Conference on Software Development and Technologies for Enhancing Accessibility and Fighting Info-Exclusion, Dsai 2013, 27, pp. 176-185 (2014). https://doi.org/10.1016/j.procs. 2014.02.021

Gonçalves, R., Pereira, J., Martins, J., Martins, J., Branco, F.: Acessibilidade web: Ponto de situação das maiores empresas portuguesas. Paper presented at the APDSI (2009)

Google: Accessibility (n.d.-a). https://google-developer-training.gitbooks.io/android-developeradvanced-course-concepts/content/unit-3-make-your-apps-accessible/lesson-6-accessibility/61-c-accessibility/6-1-c-accessibility.html

Google: Accessibility: Material Design (n.d.-b). https://material.io/design/usability/accessibility. $\mathrm{html}$

Google: Get started on Android with TalkBack (n.d.-c). https://support.google.com/accessibility/ android/answer/ $6283677 ? \mathrm{hl}=\mathrm{pt}$

Google: Primeiros passos com o Scanner de acessibilidade (n.d.-d). https://support.google.com/ accessibility/android/answer/ 6376570 ?hl=pt-BR

Harry, N., Boone, J., Boone, D.A.: Analyzing likert data. J. Extension 50, 1-3 (2012)

Henry, S.L.: Accessibility in User-Centered Design: What is Accessibility? (2007). https://www. uiaccess.com/accessucd/background.html

IDEA: Statute and Regulations (n.d.). https://sites.ed.gov/idea/statuteregulations/

Ivory, M.Y., Mankoff, J., Le, A.: Using automated tools to improve web site usage by users with diverse abilities. Hum.-Comput. Interact. Inst. 1(3), 117 (2003)

Lecheta, R.R.: Google Android: aprebda a criar aplicações para dispositivos móveis com o Android SDK. Novatec, São Paulo (2010) 
Martins, J.L.B.: Avaliação de acessibilidade dos sítios web das empresas portuguesas. UTAD (2008)

Metro do Porto: iMetro do Porto: a nova aplicação mobile grátis (n.d.). https://www. metrodoporto.pt/frontoffice/pages/513?news_id=237

Moreira, P.: Acessibilidade dos contéudos web no setor da saúde (2014)

Nações Unidas: Convention on the Rights of Persons with Disabilities and Optional Protocol (2006). https://www.un.org/disabilities/documents/convention/convoptprot-e.pdf

Parlamento Europeu and Conselho Europeu: Directive (EU) 2016/2102 of the European Parliament and of the Council of 26 October 2016 on the accessibility of the websites and mobile applications of public sector bodies (2016). https://eur-lex.europa.eu/legal-content/ EN/TXT/?qid=1481550842681\&uri=CELEX:32016L2102

Ramiro, G., Jorge, P., José, M., Frederico, B., Carlos, P.: Acessweb-uma perspetiva sobre a acessibilidade web em portugal (2015)

Santhipriya, S., Sastry, B., Akshitha, K.: Securing smartphone apps in online environment. Int. J. Math. Arch. (IJMA) 2, 2462-2469 (2011)

SNS: MySNS - SNS (n.d.). https://www.sns.gov.pt/apps/mysns/

Thatcher, J., Henry, S., et al.: Web Accessibility: Web Standards and Regulatory Compliance. friends of ED (2006)

Tomás, C.: A acessibilidade das plataformas de e-learning em instituições de ensino público em portugal: contributos iniciais (2014). https://www.panoramaelearning.pt/wp-content/uploads/ 2014/04/AcessibilidadeElearningESPP.pdf

UserLight: Color Contrast (n.d.). https://itunes.apple.com/na/app/color-contrast/id1095478187

Vector 21: Relatório vector21 sobre acessibilidade web em portugal (2008). https://www. vector21.com/?idc $=27 \&$ idi $=4953$

W3C: Web Content Accessibility Guidelines 1.0 (1999). https://www.w3.org/TR/WAIWEBCONTENT/

W3C: Web Content Accessibility Guidelines (WCAG) 2.0 (2008). https://www.w3.org/TR/ WCAG20/

W3C: WAI early days (2009). https://www.w3.org/WAI/history

W3C: Mobile Accessibility: How WCAG 2.0 and Other W3C/WAI Guidelines Apply to Mobile (2015). https://www.w3.org/TR/mobile-accessibility-mapping/

W3C: Mobile Accessibility at W3C (2017a). https://www.w3.org/WAI/standards-guidelines/ mobile/

W3C: W3C Mission (2017b). https://www.w3.org/Consortium/mission

W3C: Web Content Accessibility Guidelines (WCAG) 2.1 (2018). https://www.w3.org/TR/ WCAG21/

Wainer, J.: Métodos de pesquisa quantitativa e qualitativa para a Ciência da Computação (2018)

White, K.: Determining Accessibility for iOS Applications: Piloting a Checklist for Practitioners. University of Wisconsin-Milwaukee (2015). https://dc.uwm.edu/cgi/viewcontent.cgi?article= 2096\& context=etd

WHO: Disability and health (2018). https://www.who.int/mediacentre/factsheets/fs352/en/ 